\title{
Spatial and temporal movement patterns of a multi-species coastal reef shark aggregation
}

\author{
Conrad W. Speed ${ }^{1,2, *}$, Mark G. Meekan', Iain C. Field ${ }^{2,3}$, Clive R. McMahon $^{2}$, \\ John D. Stevens ${ }^{4}$, Frazer McGregor ${ }^{5}$, Charlie Huveneers ${ }^{6,7}$, Yuval Berger ${ }^{1}$, \\ Corey J. A. Bradshaw ${ }^{7,8}$ \\ ${ }^{1}$ Australian Institute of Marine Science, The UWA Oceans Institute (M096), 35 Stirling Hwy, Crawley, \\ Western Australia 6009, Australia \\ ${ }^{2}$ School for Environmental Research, Charles Darwin University, Darwin, Northern Territory 0909, Australia \\ ${ }^{3}$ Graduate School for the Environment, Macquarie University, New South Wales 2109, Australia \\ ${ }^{4}$ CSIRO Marine \& Atmospheric Research, Castray Esplanade, Hobart, Tasmania 7000, Australia \\ ${ }^{5}$ Murdoch University Field Station, Coral Bay, Western Australia 6701, Australia \\ ${ }^{6}$ School of Biological Sciences, Flinders University, GPO Box 2100, Adelaide, South Australia 5001, Australia \\ ${ }^{7}$ South Australian Research and Development Institute, PO Box 120, Henley Beach, South Australia 5022, Australia \\ ${ }^{8}$ The Environment Institute and School of Earth and Environmental Sciences, University of Adelaide, Adelaide, \\ South Australia 5005, Australia
}

\begin{abstract}
The quantification of spatial and temporal movement patterns of coral reef sharks is important to understand their role in reef communities and to aid the design of conservation strategies for this predatory guild. We observed 4 species of reef sharks aggregating in an inshore bay in the north of Western Australia for over 2 yr, using acoustic telemetry and visual censuses to examine how they partitioned this site in space and time. We fitted 58 sharks with acoustic transmitters: Carcharhinus melanopterus (36), C. amblyrhynchos (11), Negaprion acutidens (7) and Triaenodon obesus (4). Aggregations consisted primarily of C. melanopterus, although C. amblyrhynchos and $N$. acutidens were often present. We observed aggregations by visual census in summer (maximum of 44 sharks). Detections were highest during warmer months (Sep to Mar) for all species, although some individuals showed year-round residency. C. melanopterus, C. amblyrhynchos and $N$. acutidens had strong diel patterns of attendance at the aggregation site. Peak daily detections occurred from 13:00 to 14:00 h local time for C. melanopterus and C. amblyrhynchos; juvenile C. melanopterus and N. acutidens peaked at 05:00 and 10:00 h, respectively. There was considerable spatial overlap of core areas of use ( $50 \%$ kernel density estimates) at the northern end of the bay by all species; the southern end was used primarily by C. melanopterus and N. acutidens. Aggregations of C. melanopterus and C. amblyrhynchos consisted mainly of adult females, some of them pregnant. Courtship behaviour in $C$. melanopterus and T. obesus suggests that these aggregations are related to reproduction. All species displayed inter-annual site fidelity. The long-term presence of juvenile C. melanopterus and N. acutidens also suggests that this bay provides suitable conditions for younger age classes.
\end{abstract}

KEY WORDS: Habitat partitioning $\cdot$ Site fidelity $\cdot$ Residency $\cdot$ Acoustic telemetry $\cdot$ Visual census Management $\cdot$ Habitat use $\cdot$ Diel patterns - Resale or republication not permitted without written consent of the publisher

\section{INTRODUCTION}

Quantifying long-term movement patterns of coral reef sharks is important for understanding their role in community structure and providing baseline informa- tion for effective conservation, which is of mounting concern (Friedlander \& DeMartini 2002, Robbins et al. 2006, Heupel et al. 2010, Ward-Paige et al. 2010). The spatial and temporal shifts in movement of these predators can affect their prey both directly through 
ingestion and indirectly through predation risk (Speed et al. 2010). The presence of multiple species and size classes of reef sharks on healthy reefs (Nelson \& Johnson 1980, Stevens 1984, McKibben \& Nelson 1986, Chapman et al. 2005, DeAngelis et al 2008) suggests that coexistence arises in part because habitat partitioning occurs at some spatial and temporal scales.

There is increasing evidence that some species and size classes of sharks cohabit the same areas through habitat partitioning. Intra-specific habitat partitioning is common in some species, with many studies concluding that juveniles and adults partition habitats by depth, temperature, salinity, or benthos type (Chapman et al. 2005, Pikitch et al. 2005, Simpfendorfer et al. 2005, McAuley et al. 2007, Yeiser et al. 2008, Speed et al. 2010). However, few studies have quantified temporal and spatial habitat partitioning among different species, although there is some evidence to support inter-specific partitioning in relation to the distribution of prey (White \& Potter 2004), habitat type and season (White \& Potter 2004, DeAngelis et al. 2008). The underlying processes determining this partitioning and segregation are often related to predator avoidance and the reduction of intra- and inter-specific resource competition (Sims 2003). However, the mechanisms that allow different species and several size classes of the same species to coexist are often unclear; therefore, more species and systems need to be investigated to provide insight and to assist in management of multi-species complexes (Speed et al. 2010).

Many sharks aggregate at some point during their lives, resulting in elevated densities of a particular species, sex, or size class at some sites. Aggregations have been documented in many shark taxa, including planktivores (Sims \& Merrett 1997, Meekan et al. 2006), large predators (>4 m) (Weng et al. 2007), coastal species (Klimley \& Nelson 1981, Dudley et al. 2005, Heupel \& Simpfendorfer 2005) and reef-associated sharks (Stevens 1984, McKibben \& Nelson 1986, Gruber et al. 1988, Economakis \& Lobel 1998, Smith \& Pollard 1999, Pratt \& Carrier 2001, Whitney et al. 2004, Hight \& Lowe 2007). Aggregations have been observed in both adult and juvenile size classes for some species (e.g. Klimley \& Nelson 1984, Duncan \& Holland 2006) and often result in, or are attributable to, site fidelity and 'refuging' behaviour, where aggregations occur around a core daytime area and disperse at night (e.g. Klimley \& Nelson 1984, Economakis \& Lobel 1998, Hight \& Lowe 2007). Aggregations can also involve several species at the same time, although such inter-specific interactions have rarely been documented within the shallow waters of coral reefs (e.g. McKibben \& Nelson 1986, Gruber et al. 1988). Where multi-species aggregations of reef sharks are present, they provide an ideal opportunity to examine habitat partitioning and other inter-specific interactions. Furthermore, because aggregations can occur close to shore and individuals often show site fidelity, such behaviour allows easy access to study animals that are at other times more broadly distributed across reef environments.

Grey Carcharhinus amblyrhynchos, blacktip Carcharhinus melanopterus and whitetip Triaenodon obesus reef sharks are the most common sharks found on Indo-Pacific coral reefs (Last \& Stevens 2009). All are known to form aggregations and are co-occurring, mid-sized $(<2 \mathrm{~m}$ adult total length) and primarily piscivorous (Cortés 1999). These species, along with juvenile sicklefin lemon sharks Negaprion acutidens, are common in inshore areas of Ningaloo Reef on the north-western coast of Western Australia. In an embayment located at the southern end of Ningaloo, aggregations that include these 4 species occur during the summer months (December to February). The reasons for these aggregations are currently speculative, and no quantitative information exists on the spatial and temporal movement patterns. We hypothesise that (1) C. melanopterus, C. amblyrhynchos and T. obesus aggregate for reproductive reasons during summer, (2) C. melanopterus and $N$. acutidens also use this site as a nursery, (3) all species and size classes partition this site through space and time, (4) all species display refuging behaviour through diel patterns of attendance and (5) all species exhibit long-term site fidelity.

\section{MATERIALS AND METHODS}

Study site. Skeleton Bay ( 1.5 km long) is located within the Coral Bay region, which is on the southern part of Ningaloo Reef in northern Western Australia $\left(23^{\circ} 7^{\prime} 36^{\prime \prime} \mathrm{S}, 113^{\circ} 46^{\prime} 8^{\prime \prime} \mathrm{E}\right)$ (Fig. 1A). The bay is managed as a no-take marine protected area by the Western Australian Government's Department of Environment and Conservation, where commercial and recreational fishing and boat mooring are prohibited. Skeleton Bay is dominated by shallow (1 to $3 \mathrm{~m}$ ) coral reef habitats and sand flats. Two ridges of reef run parallel to the shore in a north-south direction, of which the outer is partially exposed at low tide. Sand flats at the southern end of the bay become exposed during spring low tides.

Tagging. During November and December of 2007 to 2009 and August 2009, we caught 58 sharks from the beach at Skeleton Bay using hand reels and baited barbless hooks. We then transported caught sharks to the beach and restrained them in a holding tank, where they were turned upside down to induce a state of tonic immobility. We then implanted acoustic tags V13-1H (153 dB), V16-5H (165 dB) and V16-5x 

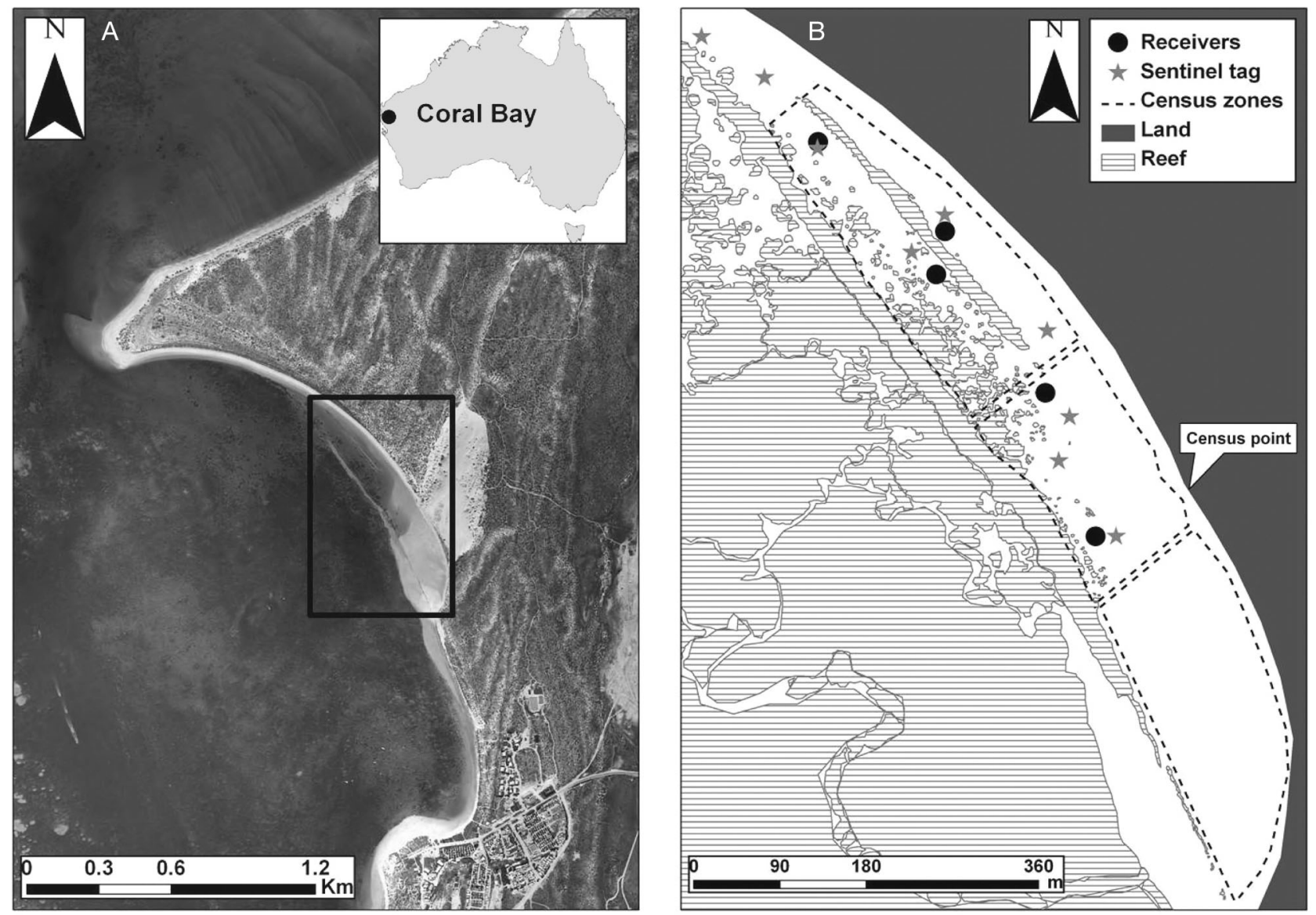

Fig. 1. (A) Coral Bay region, showing Skeleton Bay (black rectangle); (B) a detailed view of Skeleton Bay, showing the receiver and sentinel tag locations, as well as the visual census observation point and zones

$(165 \mathrm{~dB})$; Vemco - coated in beeswax in the peritoneal cavity (see Heupel et al. 2006). V13 and V16 tags had an approximate battery life of 1.5 and $3.5 \mathrm{yr}$, respectively. We used V13 tags for all animals tagged in 2007 , $\sim 36 \%$ of the individuals in 2008 and $\sim 33 \%$ of the individuals in 2009. We used both models of V16 tags in 2008 and 2009. We attached jumbo rototags (Dalton Supplies) to the dorsal fin to permit rapid identification of any recaptured individuals. We recorded species, sex and total length $\left(L_{\mathrm{T}}\right)$ in metres and made observations of scarring and the condition of each tagged shark. We assessed life-history stages (i.e. juvenile or adult) based on $L_{\mathrm{T}}$ and previously established size-atmaturity data (Last \& Stevens 2009).

Visual census. To complement acoustic detections for examining aggregations, we counted the number of sharks at the aggregation site in Skeleton Bay hourly if possible between 08:00 and 17:00 h for $25 \mathrm{~d}$ in November/December 2008, 19 d in November/December 2009, 4 d in August 2009 and 4 d in February 2010, from the top of a sand dune at the back of the beach (Fig. 1B). We often censused sporadically around shark tagging; therefore, we did not census at exact hourly intervals. We chose the times between 10:00 and $17: 00 \mathrm{~h}$ as the most appropriate for censuses because the sun was in the optimal position for minimal glare on the water. We divided the bay into 3 zones (south, mid and north) using prominent land marks. We define an 'aggregation' as 5 or more individuals being present in the same zone at the same time (Heupel \& Simpfendorfer 2005). We minimised double counting of individuals by counting left to right within each zone rapidly, which avoided the likelihood of individuals moving across zones during each census period. A summary of the date, timing and number of counts is given in Table $\mathrm{S} 1$ in the supplement at www.intres.com/articles/suppl/m429p261_supp.pdf. We tested the sensitivity of our results to the choice of 5 individuals as an 'aggregation' by modifying this threshold from 3 to 15 individuals. The visual census also enabled a comparison of numbers of sharks with the number of tagged individuals detected by the acoustic array during the period from November to December 2008 and 2009. Assuming a tagged animal was counted during a census and was also detected by at least 1 of the receivers, we could calculate the total 
percentage of tagged animals at the aggregation site (number of individuals detected in the array within each census period divided by the total number of animals counted in all zones in each census). We also compared the combined counts of all zones with the total number of individuals detected by the array during the same time using linear models. We contrasted the slope model (detections $\sim$ census) and interceptonly model (detections 1) using Akaike's information criterion (corrected for sample size) weights $\left(\mathrm{wAIC}_{\mathrm{c}}\right.$ ) (Burnham \& Anderson 2002).

Receiver range and sentinel tag testing. We deployed an array of 5 acoustic receivers (VR2w, Vemco) to monitor movement patterns of tagged sharks (Fig. 1B). We anchored receivers to the substratum using cement-filled car tyres with a single metal bar (50 $\mathrm{cm}$ tall) through the centre, to which the receiver was attached. Monitoring occurred from November 2007 to February 2010. We tested the detection range of each receiver in 2007 prior to tag deployment by swimming a test pinger (V16 Model 147, Vemco) with a ping rate of $1 \mathrm{~Hz}$ along a predetermined path within the array for validation, during which time we recorded the tag location at $50 \mathrm{~m}$ intervals using a handheld GPS (accurate to $\pm 5 \mathrm{~m}$ ). We range-tested the pingers during a flowing tide when winds were $<15$ knots. We calculated minimum convex polygons for each receiver to determine the detection range and degree of overlap (Simpfendorfer et al. 2002). The detection range of receivers depends partly on the output strength of the tags used within an array (VEMCO 2007). Therefore, the receiver detection range for V13 tags would have been less than the detection ranges calculated in the present study, which were based on V16 tags.

We estimated shark positions using a custom algorithm (Simpfendorfer et al. 2002, Heupel \& Simpfendorfer 2005); however, because it was developed with a different species in a different environment, we estimated the associated error in the array by deploying a 'sentinel' tag (V16-5H coded pinger, Vemco, 120 to 240 s ping rate) at 9 locations within the array. We attached the sentinel tag to a monofilament nylon line and positioned it $50 \mathrm{~cm}$ above the bottom using a float and weight. We recorded each deployment position with a GPS and left the tag in place for periods of 1 to 10 d during November 2009 (Fig. 1B). We estimated the associated error by calculating the mean great-circle distance between sentinel tag deployments and the tag position estimates for each of the 9 locations.

Receiver performance. It was essential to examine receiver performance due to the large number of tagged individuals aggregating at the site and the shallow, complex reef habitat. We used 3 metrics developed by Simpfendorfer et al. (2008): (1) code detection efficiency, (2) rejection coefficient and (3) noise quotient. The code detection efficiency provided information on the percentage of tagged animals present that had valid detections (consisting of a 7-pulse code sequence), while the rejection coefficient provided an estimate of rejected detections due to incomplete codes. Finally, the noise quotient provided an estimate of detection errors due to tag code collisions and/or environmental noise (negative values $=$ tag collision ; positive values $=$ environmental noise) $($ Simpfendorfer et al. 2008).

Spatial analysis. We calculated short-term centres of activity (30 min periods) for each tagged shark at the aggregation site using the algorithm by Simpfendorfer et al. (2002). The algorithm relies on multiple detections of an individual by different receivers and provides a centre of activity estimate based on weighted means from the detections for the desired period (Simpfendorfer et al. 2002). We calculated kernel density (KD) estimates (50 and $95 \%$ ) for each individual to provide 'core area' and 'total area' of use, respectively, while at the study site (see Beyer 2004). We then overlayed individual KDs to provide core and total area of use per species. We calculated the KD overlap among all individuals using the centres of activity and then took the average for each species. The mean species KD overlap values are indices of the amount of overlap each species has with another, 0 being no overlap and 1 being $100 \%$ overlap. We calculated a same-spaceuse probability to assess the amount of each kernel shared by 2 individuals. This was done by using the following expression:

$$
(x / 100)^{2} y
$$

where $x$ is the kernel size and $y$ is the pair-wise kernel overlap. Thus, the combined probability is the average probability that the species a individual is within its kernel range, multiplied by the probability that the species $b$ individual is within its kernel range, multiplied by the spatial overlap. We then calculated the mean same-space-use probability among each species for 25, 50, 75 and $95 \%$ KD overlap.

Temporal analysis. We used the receiver array detections to describe the temporal patterns of use of the aggregation site through time. If an individual had $>1$ detection $\mathrm{d}^{-1}$ at the aggregation site, we recorded it as present. We calculated residency by dividing the number of days an animal was present at the study site by the total number of days since it was tagged. We also calculated mean hourly detections per month to demonstrate fluctuations in the number of individuals present throughout the 28 mo monitoring period. We applied a fast-Fourier transformation (Chatfield 1996) to analyse diel patterns in visitation by sharks to the array. We also standardised total detections per hour 
throughout the $24 \mathrm{~h}$ cycle by dividing the total number of detections per hour by the number of individuals present within the same hour for each species and size class. We did all analyses using a combination of the programs R (adehabitat package), Matlab, Microsoft Access and ArcGIS (Hawth's tools).

\section{RESULTS}

\section{Shark tagging}

The average $( \pm \mathrm{SE})$ time from capture to release after tagging was $12.3 \pm 0.4 \mathrm{~min}$. All sharks swam well after release and were subsequently detected by the array, implying that the tagging process did not harm animals, at least over the duration of the study (28 mo). Only 1 shark was detected for $<24 \mathrm{~h}$, which was tagged with a transmitter that had been returned by a recreational fisher from a recaptured shark (Tag 8329 -tagged 22 November 2008) (Table S2 in the supplement at www.int-res.com/articles/suppl/m429 p261_supp.pdf). A total of 58 sharks were tagged from 4 species at Skeleton Bay over the 3 tagging periods (Table 1; Table S2 in the supplement). Overall, more females than males were caught $(34: 24=1.42: 1)$, and Carcharhinus melanopterus was the most commonly tagged shark (36). The sex ratio of C. melanopterus changed to a 3:1 ratio of males to females in the third year of sampling because we targeted males for acoustic tag implantation to increase the sample size of this sex. The average $( \pm \mathrm{SD}) L_{\mathrm{T}}$ of $C$. melanopterus tagged between November and December 2007, 2008 and 2009 was $1.13 \pm 0.32,1.29 \pm 0.13$ and $1.03 \pm 0.16 \mathrm{~m}$, respectively, indicating that the majority of tagged sharks of this species were mature adults (Table 1). We

Table 1. Summary of reef sharks tagged with acoustic transmitters in Skeleton Bay. $L_{\mathrm{T}}$ : total length

\begin{tabular}{|llccc|}
\hline $\begin{array}{l}\text { Year } \\
\text { tagged }\end{array}$ & Species & $\begin{array}{c}L_{\mathrm{T}}(\mathrm{m}, \\
\text { mean } \pm \mathrm{SD})\end{array}$ & $\begin{array}{c}\text { Males } \\
(\mathrm{n})\end{array}$ & $\begin{array}{c}\text { Females } \\
(\mathrm{n})\end{array}$ \\
\hline 2007 & Carcharhinus amblyrhynchos & $1.46 \pm 0.00$ & 0 & 1 \\
& Carcharhinus melanopterus & $1.13 \pm 0.32$ & 1 & 7 \\
& Negaprion acutidens & $1.21 \pm 0.00$ & 1 & 0 \\
\multirow{2}{*}{2008} & C. amblyrhynchos & $1.46 \pm 0.23$ & 1 & 7 \\
& C. melanopterus & $1.29 \pm 0.13$ & 9 & 15 \\
& N. acutidens & $1.20 \pm 0.31$ & 4 & 1 \\
& Triaenodon obesus & $1.39 \pm 0.42$ & 2 & 0 \\
& C. amblyrhynchos & $1.55 \pm 0.85$ & 0 & 2 \\
& C. melanopterus & $1.03 \pm 0.16$ & 3 & 1 \\
& N. acutidens & $1.03 \pm 0.00$ & 1 & 0 \\
& T. obesus & $1.28 \pm 0.42$ & 2 & 0 \\
& & 1.27 & 24 & 34 \\
\hline
\end{tabular}

caught $11 C$. amblyrhynchos, of which 9 were mature $\left(L_{\mathrm{T}}=1.46 \pm 0,1.46 \pm 0.23\right.$ and $1.55 \pm 0.85 \mathrm{~m}$ for each of the tagging trips from November to December, respectively) and 10 were females. We caught 7 juvenile Negaprion acutidens $\left(L_{\mathrm{T}}=1.21 \pm 0,1.20 \pm 0.31\right.$ and $1.03 \pm 0 \mathrm{~m}$ for each of the tagging trips from November to December, respectively), of which 6 were males. We caught 4 adult male Triaenodon obesus that averaged $\left( \pm\right.$ SD) $1.39 \pm 0.42 \mathrm{~m} L_{\mathrm{T}}$ in 2008 and $1.28 \pm 0.42 \mathrm{~m} L_{\mathrm{T}}$ in 2009. Mating females were identified by recent scarring and were common within aggregations, as were gravid females. We did not observe any scars on C. amblyrhynchos.

\section{Visual census}

We did 158 censuses, of which approximately 90\% were done by C. W. Speed; the other $10 \%$ were done under the guidance of C. W. Speed. We counted a maximum of 44 sharks in an aggregation, and the maximum number in any 1 census period (all 3 zones combined) was 74; both maxima were recorded in November of 2008 (Table S1 in the supplement). We observed an aggregation in at least 1 zone within the bay during approximately $62 \%$ of censuses. Sensitivity tests indicated that aggregation percentages ranged between approximately $68 \%$ (3 individuals) and 30\% (15 individuals). Aggregations were more common in the south $(54.7 \%$ of censuses) than in the mid $(14.4 \%)$ or north zones $(18.9 \%)$. This pattern remained unchanged during sensitivity tests. Multiple aggregations (i.e. an aggregation in >1 zone) occurred in $22.6 \%$ of all censuses and ranged between $34.8 \%$ (3 individuals) and $3.8 \%$ (15 individuals).

We used only census periods between 10:00 and 17:00 h $(\mathrm{n}=144)$ to calculate mean estimates of shark abundance per zone because counts outside of these times were sporadic. There was a bimodal peak in the mean number of individuals in the south zone between 13:00 and 13:59 $\mathrm{h}$ and between 16:00 and 16:59 h (Fig. 2). There was also a peak in the mean numbers of individuals in the north zone from 15:00 to $15: 59 \mathrm{~h}$. The south zone consistently had a greater mean number of individuals per census period than did the mid or north zone $\left(G_{\mathrm{q}}=96.22, \mathrm{p} \ll 0.001\right.$, $G$-test of independence; Sokal \& Rohlf 1995).

Overall, tagged animals made up approximately $30 \%$ of the sharks we 
counted in the bay. We confirmed support for a positive relationship between individuals counted per census and individuals detected by the array by comparing linear models: the slope model was ranked much higher (Akaike's information criterion: ${ } \mathrm{AIC}_{\mathrm{C}}=0.998$ ), explaining $7.3 \%$ of the deviation, than the null model $\left({ }^{2} \mathrm{AIC}_{\mathrm{c}}=0.001\right)$, which explained $8.0 \%$ of the deviation.

\section{Receiver range and sentinel tag testing}

There was considerable overlap of detection range for most receivers, with the exception of the southernand northern-most receivers with each other (Fig. S1 in the supplement at www.int-res.com/articles/suppl/ m429p261_supp.pdf). The mean maximum detection range for all receivers was approximately $280 \mathrm{~m}$, and the maximum detection range of $331 \mathrm{~m}$ was obtained by the receiver Mid 2. The range overlap suggested that estimates could be calculated by the centre of activity algorithm in most parts of the array, but were least reliable at the northern and southern ends due to lower overlap of receiver ranges.

The average $( \pm \mathrm{SE})$ error associated with sentinel tag positions and estimated positions using the centre of activity algorithm was $110 \pm 20 \mathrm{~m}$. The 2 positions with the highest error (test numbers 3 and 5) both had mean distances $>200 \mathrm{~m}$ (Fig. S2 in the supplement), and were the 2 most northerly test positions (Fig. 1B).

\section{Receiver performance}

The code detection efficiency range for receivers varied between 0 and 0.966 . The average $( \pm \mathrm{SE})$ detection efficiency for all 5 receivers was $0.56 \pm 0.002$, which suggests that over half of the codes transmitted were successfully detected (Fig. 3A). Receiver Mid 2 had the lowest mean detection efficiency and showed a sharp drop in May 2008. The overall detection efficiency trend for all receivers was approximately stable over time; however, there was a noticeable drop between October 2008 and June 2009. The rejection coefficient for receivers ranged between 0 and 0.5 and averaged $0.012 \pm 0.0002$ (Fig. 3B). There was a collective peak in the rejection coefficient between November 2008 and March 2009, although the overall trend suggests a steady increase over time.

The noise quotient varied from -20860 to 865 . Almost half of the noise quotients (2001 of 4158) were negative, suggesting that tag signal collision was a potential problem (Fig. 3C). There was a sharp drop in the mean noise quotient of receiver Mid 2 during May of 2008, which corresponds to the drop in mean detection efficiency. In 2009 there was a considerable drop in the mean noise quotient for both receivers South and Mid 1 after November, which corresponds to a sharp increase in the number of detections at both of these receivers (Fig. S3 in the supplement). This also suggests problems due to a collision of tag signals.

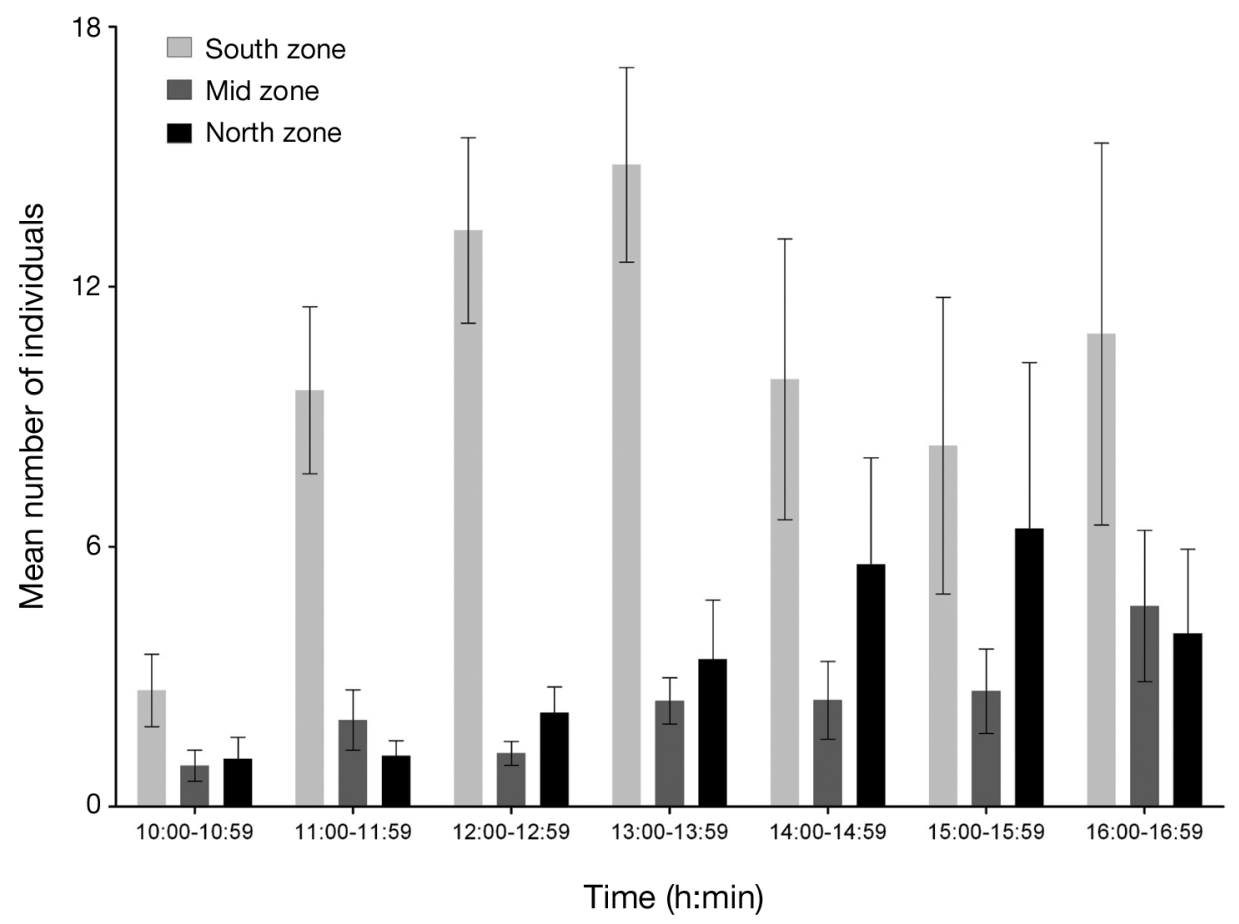

Fig. 2. Mean number $( \pm \mathrm{SE})$ of individuals in census zones at the study site 

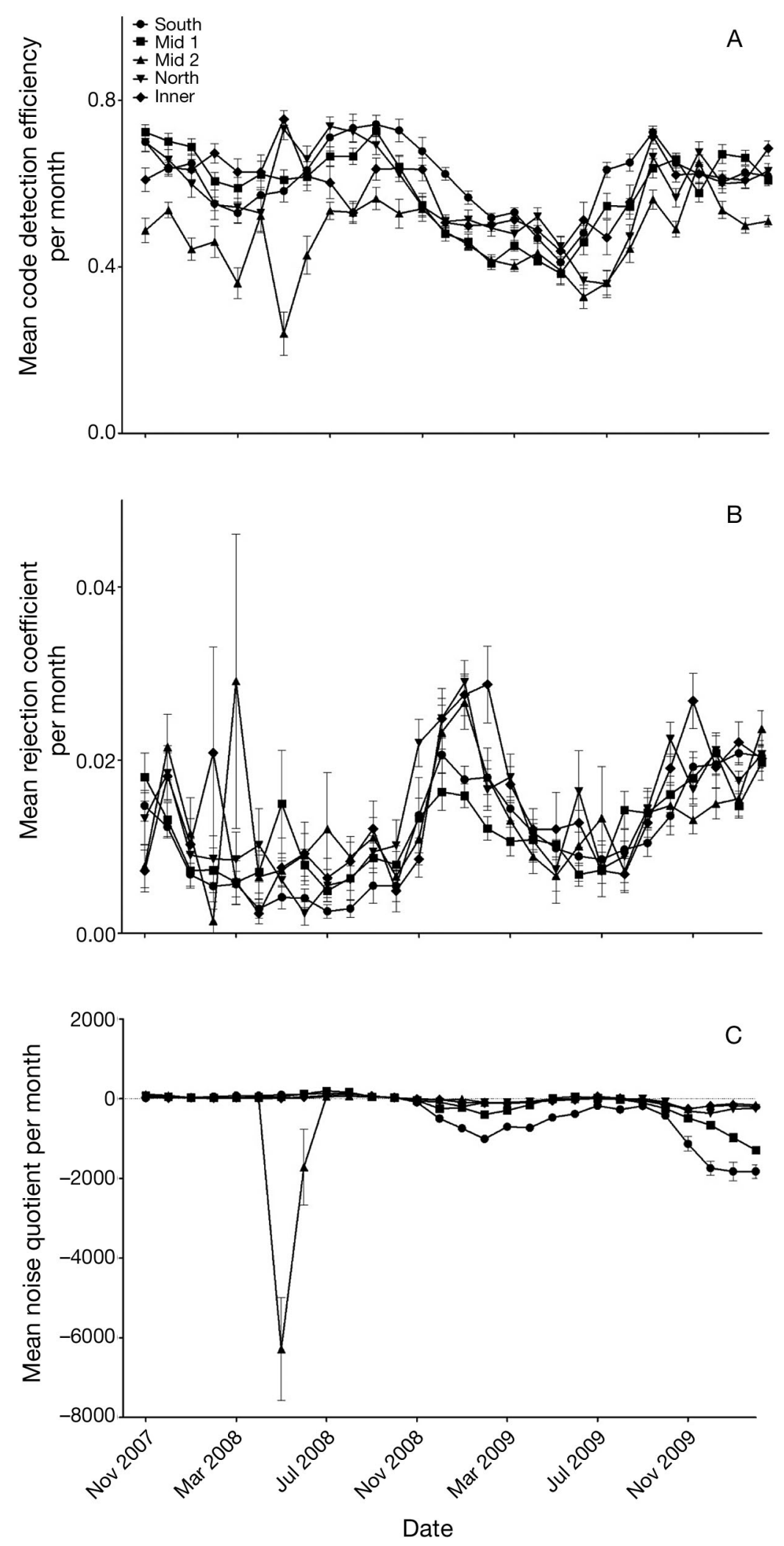

Fig. 3. Individual receiver performance metrics for the study site through time, showing (A) mean code detection efficiency, (B) mean rejection coefficient and $(C)$ mean noise quotient. Error bars show \pm SE

\section{Spatial analysis}

KDs based on short-term centres of activity within the aggregation site indicated high spatial overlap for each species in their 95\% KD estimates (Fig. 4, Table 2); this demonstrates that all 4 species were found throughout the array. We found the highest 95\% KD overlap $(0.93 \pm 0.03$, mean $\pm \mathrm{SE})$ between Carcharhinus amblyrhynchos and Triaenodon obesus, and the lowest overlap was between $C$. melanopterus and C. amblyrhynchos $(0.36 \pm 0.02)$. The $50 \% \mathrm{KD}$ estimates had considerably less overlap in core areas of use among species. C. melanopterus had 2 main areas of core use, which were at the southern and northern ends of the array, while C. amblyrhynchos and $T$. obesus mostly used the northern end of the array. In contrast, Negaprion acutidens appeared to use the southern end of the array frequently. C. amblyrhynchos and T. obesus had the highest $50 \%$ KD overlap (0.88 \pm 0.04$)$, and C. melanopterus and C. amblyrhynchos had the lowest $(0.23 \pm 0.01)$. The mean same-space-use probability identified that within KD estimates for C. amblyrhynchos and T. obesus had the highest values $(50 \%$ KD overlap $0.22 \pm 0.01$ and $95 \%$ KD overlap $0.84 \pm 0.03$, mean \pm $\mathrm{SE}$ (Fig. S4 in the supplement). We found little difference between total 50 and $95 \%$ KD estimates for the study period when compared to seasonal estimates (spring and summer), although both C. amblyrhynchos and T. obesus used the southern end of the array less in spring than in summer (Figs. S5 \& S6 in the supplement). There were too few data for C. amblyrhynchos and T. obesus to analyse KD differences among species in autumn and winter.

\section{Temporal analysis}

Of the 10 sharks tagged in 2007, 3 adult female and 1 juvenile Carcharhinus melanopterus were detected regularly until April/May of 2009, at which time the batteries in the tags (1.5 yr) expired and detections ceased (Fig. 5). Another adult female $C$. melanopterus was absent 

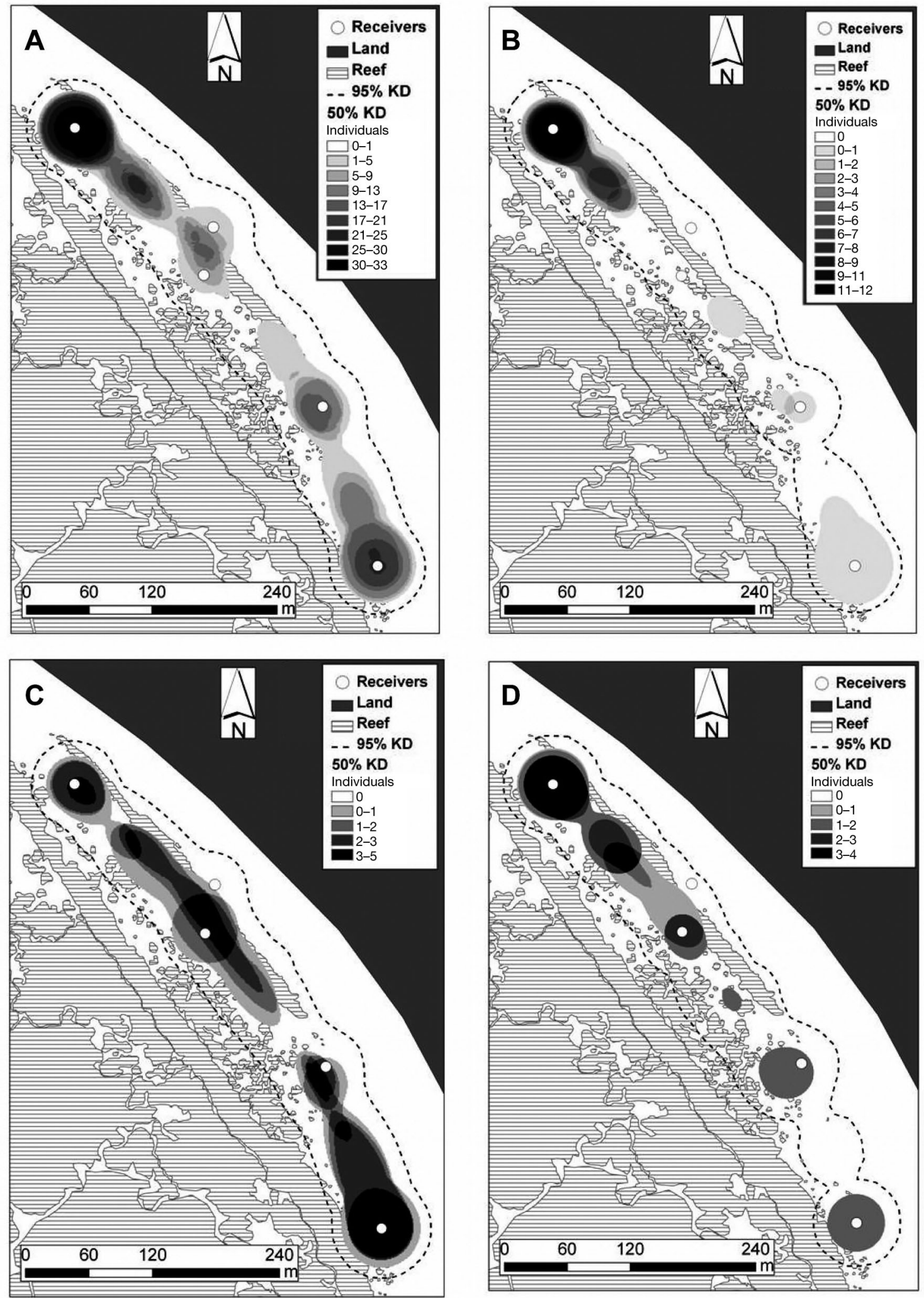

Fig. 4. Kernel density (KD) estimates per species for (A) Carcharhinus melanopterus, (B) Carcharhinus amblyrhynchos, (C) Negaprion acutidens and (D) Triaenodon obesus, based on position estimates calculated by a centre of activity algorithm. The $95 \%$ KD estimate contour is the outer boundary of combined individuals. Species $50 \% \mathrm{KD}$ estimates show combined individual densities 
Table 2. Mean $( \pm \mathrm{SE})$ kernel density $(\mathrm{KD})$ overlap between species at the aggregation site

\begin{tabular}{|c|c|c|c|c|c|c|c|c|}
\hline Species comparison & $25 \% \mathrm{KD}$ & $\mathrm{SE}$ & $50 \% \mathrm{KD}$ & $\mathrm{SE}$ & $75 \% \mathrm{KD}$ & $\mathrm{SE}$ & $95 \% \mathrm{KD}$ & $\mathrm{SE}$ \\
\hline Carcharhinus melanopterus \& Carcharhinus amblyrhynchos & 0.17 & 0.01 & 0.23 & 0.01 & 0.29 & 0.02 & 0.36 & 0.02 \\
\hline C. melanopterus \& Triaenodon obesus & 0.52 & 0.03 & 0.62 & 0.03 & 0.73 & 0.02 & 0.85 & 0.02 \\
\hline C. melanopterus \& Negaprion acutidens & 0.20 & 0.02 & 0.35 & 0.02 & 0.52 & 0.02 & 0.65 & 0.01 \\
\hline C. amblyrhynchos \& T. obesus & 0.82 & 0.06 & 0.88 & 0.05 & 0.91 & 0.04 & 0.93 & 0.03 \\
\hline C. amblyrhynchos \& N. acutidens & 0.27 & 0.04 & 0.38 & 0.05 & 0.56 & 0.05 & 0.82 & 0.03 \\
\hline T. obesus \& $N$. acutidens & 0.16 & 0.05 & 0.31 & 0.07 & 0.43 & 0.06 & 0.59 & 0.05 \\
\hline
\end{tabular}

between March and September of 2008. The C. amblyrhynchos tagged in 2007 was only detected regularly until March of the following year. The C. amblyrhynchos tagged in 2008 also showed a similar pattern, although their detections stopped in February of 2009. The C. amblyrhynchos tagged in 2008 were almost never detected after this period until October of 2009. A similar pattern was observed for $46 \%$ (11) of the C. melanopterus tagged in 2008, but they generally started being detected again by the array from September of 2009. However, some of the adult female C. melanopterus (5) were detected throughout the year (residency time range $=37.9$ to $72.5 \%$ ), suggesting a high level of residency for at least some individuals of this species (Table S2 in the supplement). Two of the 5 Negaprion acutidens tagged in 2008 were also detected almost constantly throughout the year, suggesting high residency (67.4 and 99.4\%). Two of the remaining $N$. acutidens were no longer detected regularly in June and then resumed detections after October 2009; at the same time, C. amblyrhynchos also resumed use of the bay. One of the 2 Triaenodon obesus tagged in 2008 was detected often throughout 2009. In 2009, the same individual started being detected almost daily after October, as did the other T. obesus tagged in 2008. With the exception of one of the 2 T. obesus tagged in 2009, all other sharks tagged in November/ December 2009 (7) were detected regu-

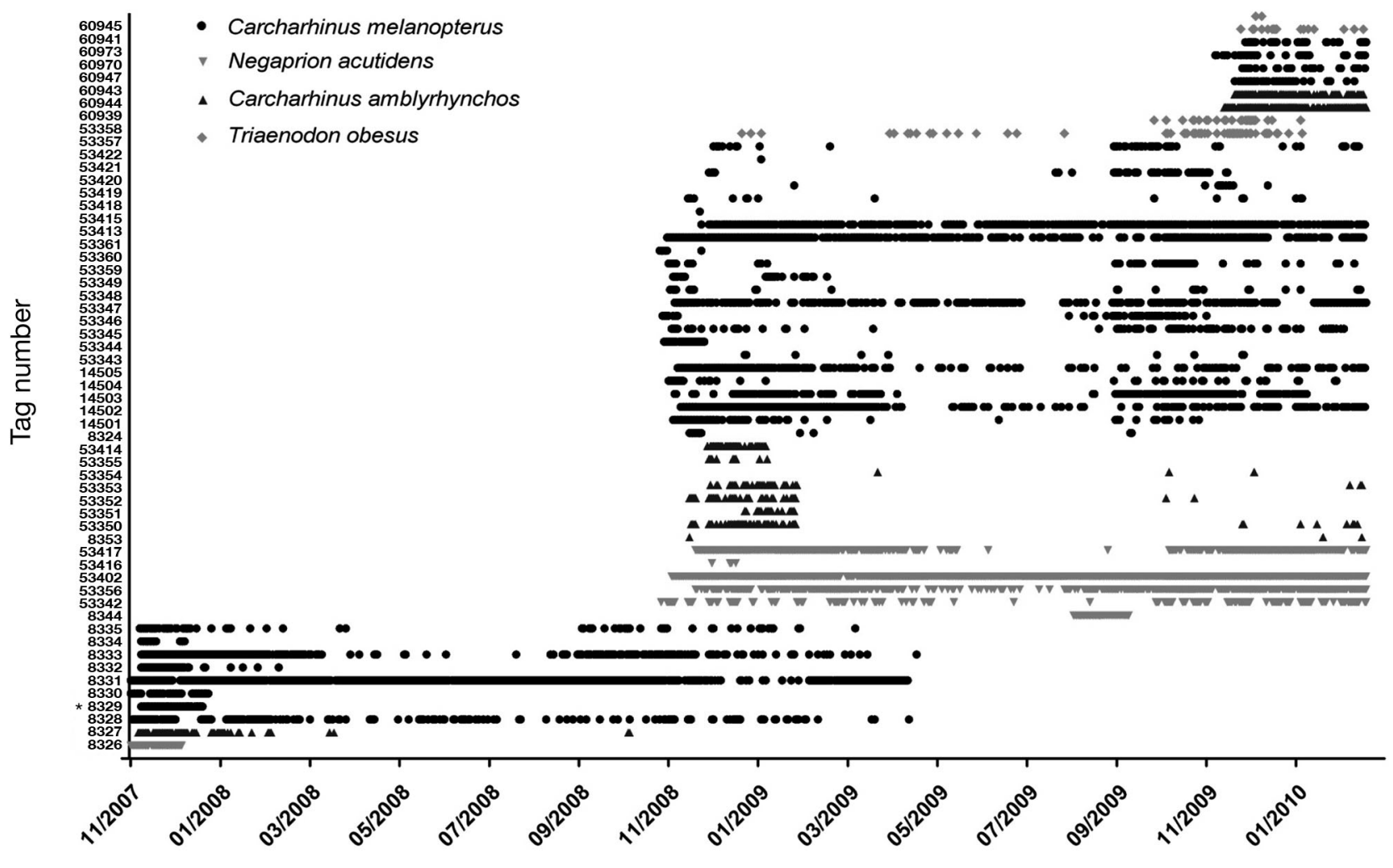

Date (mo/yr)

Fig. 5. Presence of tagged sharks (57) through time at the study site based on multiple daily detections. *Only detections from the initial tag deployment are included 

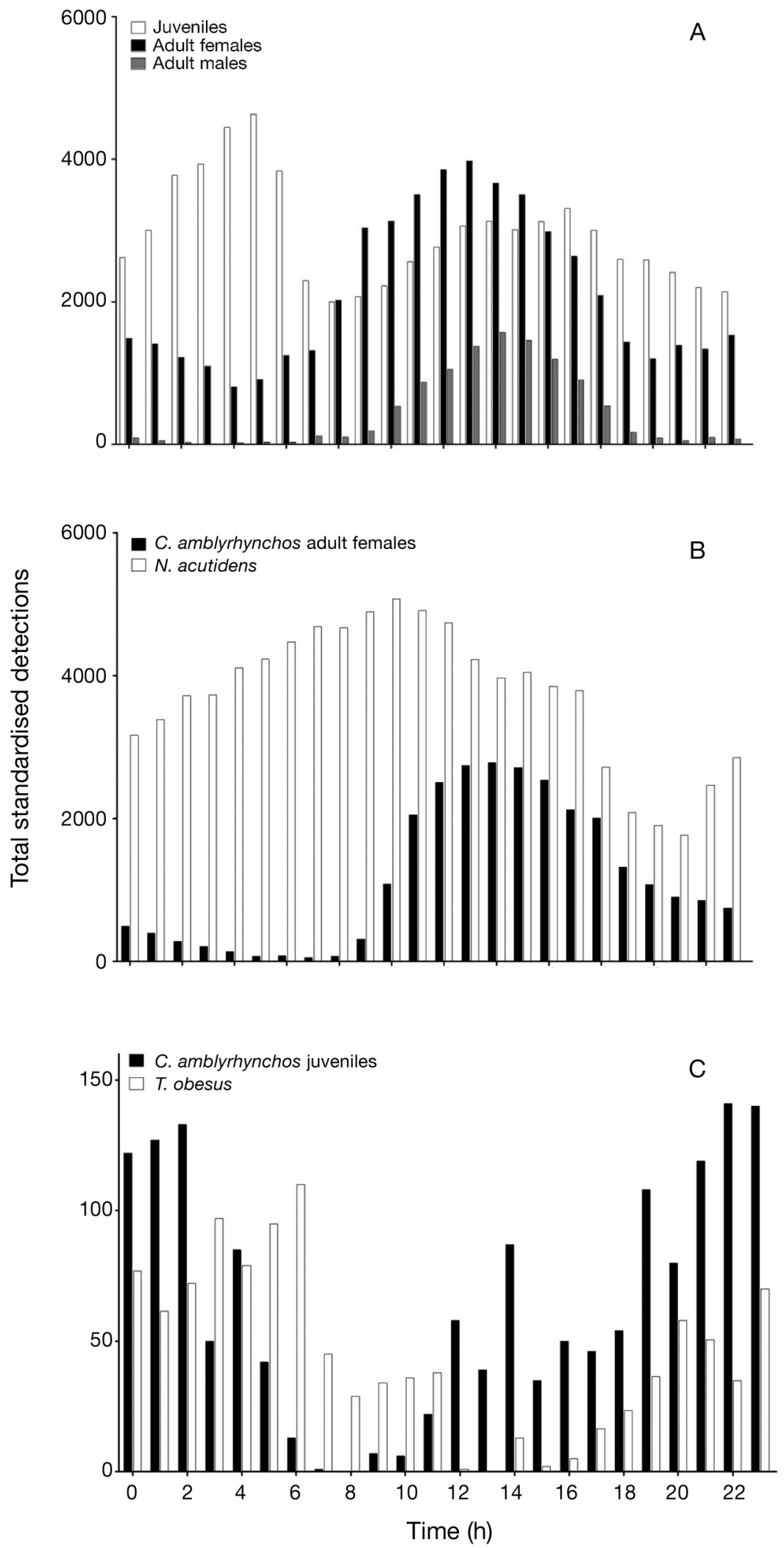

Fig. 6. Combined hourly standardised detections of (A) Carcharhinus melanopterus, (B) Carcharhinus amblyrhynchos and Negaprion acutidens and (C) C. amblyrhynchos and Triaenodon obesus at the study site larly up until the last download of the receiver array at the end of February 2010. Of the 39 sharks tagged in 2008, 22 sharks-C. melanopterus (12), $C$. amblyrhynchos (4), N. acutidens (4), and T. obesus (2) - were detected in both 2009 and 2010, demonstrating high site fidelity across years. In general, all species showed higher residency in summer and spring than in autumn and winter (Fig. S7 in the supplement).

There was a peak in total standardised detections (combined detections $\mathrm{h}^{-1}$ / number of individuals $\mathrm{h}^{-1}$ ) of both adult male Carcharhinus melanopterus and adult female C. amblyrhynchos around $14.00 \mathrm{~h}$, while detections of adult female C. melanopterus peaked at $13.00 \mathrm{~h}$ (Fig. 6A, B). Juvenile C. melanopterus and Negaprion acutidens peaked at 05:00 and 10.00 h, respectively. We observed no diel pattern or hourly detection peak for Triaenodon obesus or the juvenile C. amblyrhynchos (Fig. 6C). Standardised detections for adult female C. amblyrhynchos were relatively low in the early (00:00 to 10:00 h) morning, compared to afternoon and night. Total standardised detections of juvenile $N$. acutidens and juvenile C. melanopterus were usually $>2000$ individuals $\mathrm{h}^{-1}$. Mean hourly detections of individuals detected by the array at the study site per month were highest between November and February across years (Fig. S8 in the supplement).

Results from the fast-Fourier analysis indicated strong $24 \mathrm{~h}$ cycles in detections of Carcharhinus melanopterus and $C$. amblyrhynchos, as well as of juvenile Negaprion acutidens that were tagged in 2008 (Fig. 7). Clear $24 \mathrm{~h}$ peaks were present in $>65 \%(\mathrm{n}=15)$ of adult $C$. melanopterus, $71 \%(\mathrm{n}=5)$ of adult $C$. amblyrhynchos and $80 \%(n=4)$ of juvenile $N$. acutidens; too few data for many of the other sharks prevented analysis. Smaller $12 \mathrm{~h}$ peaks were also present for these 3 species, which might have been due to the influence of tides or as a result of harmonic artefacts of $24 \mathrm{~h}$ peaks. Because of the clear presence of $24 \mathrm{~h}$ cycles, a smoothing function, such as a hamming window, was not necessary. We obtained too few data from Triaenodon obesus for meaningful analysis. 


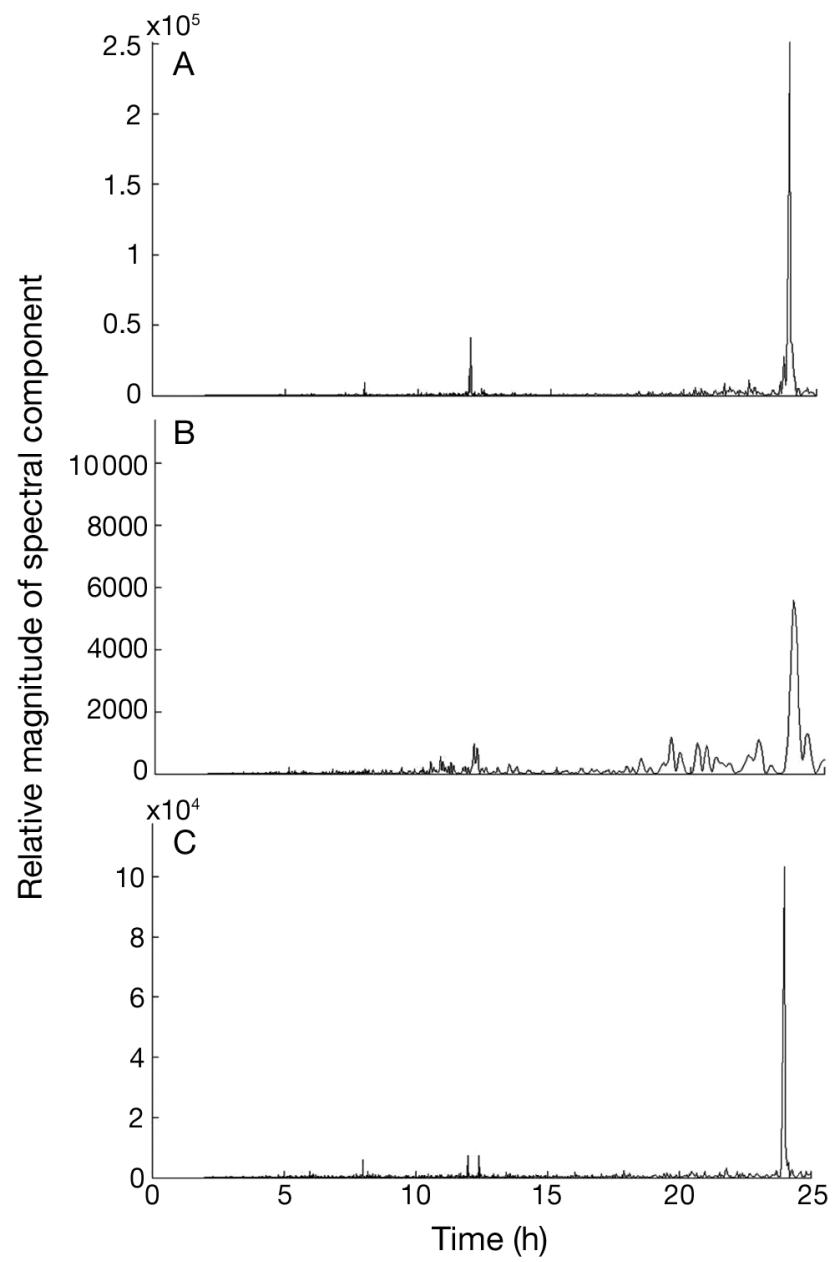

Fig. 7. Diel patterns of: (A) adult Carcharhinus melanopterus (23), (B) adult Carcharhinus amblyrhynchos (6) and (C) juvenile Negaprion acutidens (5). The datasets used were from individuals tagged in 2008

\section{DISCUSSION}

Conspecific aggregations of reef sharks in the shallow waters of coral reefs might be common, but many records of this phenomenon to date have been anecdotal. Our study presents long-term quantitative spatial and temporal information of a multi-species reef shark aggregation. Several hypotheses have been posed to explain reef shark aggregations, such as refuging (Klimley \& Nelson 1984), predator avoidance (Wetherbee et al. 2007), courtship, mating and pre-pupping (McKibben \& Nelson 1986). Previous studies of daytime aggregations of reef-associated sharks suggested that aggregations were for behavioural thermoregulation to aid embryonic development or to avoid aggressive males (Economakis \& Lobel 1998, Hight \& Lowe 2007). Aggregations of reef sharks at Ningaloo could indeed be facilitating thermoregulation, although potential courtship behaviour was also observed in Carcharhinus melanopterus and Triaenodon obesus, as has been found elsewhere (e.g. Johnson \& Nelson 1978, Whitney et al. 2004, McCauley et al. 2010), indicating that these species might be using this area for mating. The presence of both adult male and female C. melanopterus, which included gravid and freshly scarred females (described by Porcher 2005), provides additional evidence of reproductive activity for this species. Most of the C. amblyrhynchos we monitored were adult females, although we observed no courtship behaviour or evidence of mating scars. Consistent detections of juvenile C. melanopterus and Negaprion acutidens over multiple years in the bay provide some evidence that this area might be a nursery for these species, although low sample sizes and a lack of neonates makes this classification tenuous (Heupel et al. 2007). However, near-shore sand flats at other sites have been previously identified as nurseries for both C. melanopterus (e.g. Papastamatiou et al. 2009b) and N. acutidens (e.g. White \& Potter 2004).

Due to the high visibility, proximity of aggregations to shore and regularly exposed dorsal fins at the surface, it was possible to confirm that aggregations were predominantly comprised of adult Carcharhinus melanopterus. This was also reflected in the tagging results, with C. melanopterus adults constituting the majority of the catch $(62 \%)$. A total of 44 sharks counted in a single aggregation ( 74 sharks combined across all census zones) was less than the maximum number of aggregating $C$. amblyrhynchos females recorded at Johnston Atoll (160) (Economakis \& Lobel 1998), although the number was comparable to aggregations of female leopard sharks Triakis semifasciata at Santa Catalina Island (36) (Hight \& Lowe 2007). Unlike those studies, not all sharks we monitored were adult females, although tagging results suggest that there was a predominance of this sex and size class in C. melanopterus and C. amblyrhynchos. Inshore aggregations of $C$. melanopterus reef sharks have been observed in other locations, such as the Marshall Islands (Randall \& Helfman 1973) and Aldabra Atoll (Stevens 1984), and juvenile aggregations have been observed at Palmyra Atoll (Papastamatiou et al. 2009b). We tagged only 4 juvenile $C$. melanopterus, which is surprising given it is thought that females give birth in northern Australia in November (Last \& Stevens 2009). However, we caught juvenile $C$. melanopterus using nets in Skeleton Bay during November 2007 in another study, which suggests that our capture technique was inadequate to capture more of this size class in the present study (C. W. Speed et al. unpubl. data).

All species of sharks monitored by the acoustic array were regularly detected during summer (December to February), indicating a high temporal overlap of all 
species during this season. Apart from Carcharhinus amblyrhynchos, all other species monitored were present in Skeleton Bay regularly throughout the year. We observed 2 long-term patterns of residency for C. melanopterus: those that were regularly detected throughout most of the year (adult females and 1 juvenile male) and those that were generally absent from the area between March and September (males and females). We observed similar residency patterns in C. amblyrhynchos and Triaenodon obesus, except these 2 species usually started being detected from October. Immature Negaprion acutidens also displayed variants of both of these residency patterns seen in C. melanopterus. Varying patterns in individual site fidelity and movement have been observed within a number of species of reef sharks (McKibben \& Nelson 1986, Heupel et al. 2010, Papastamatiou et al. 2010, Field et al. 2011) and are often attributed to ontogeny, reproduction, or seasonal changes in habitat use. The differences in residency among female C. melanopterus in Skeleton Bay might be due to reproductive status, as pupping occurs biennially at Aldabra (Last \& Stevens 2009), although it is thought to occur annually in northern Australia (Lyle 1987, Last \& Stevens 2009). An increase in the abundance of individuals in summer was also observed in aggregations of $T$. semifasciata at Santa Catalina Island (Hight \& Lowe 2007). Similarly, aggregations of C. amblyrhynchos at Johnston Atoll were seasonal, with aggregations being present between late February and May (Economakis \& Lobel 1998), which is a similar residency period to that we observed. While shark numbers and residency were generally highest during summer in Skeleton Bay, we also observed aggregations in winter.

Skeleton Bay is likely an important habitat for reef shark reproduction and might also provide suitable conditions for younger age classes, although the mechanisms of habitat partitioning among species are still unclear. One method by which sharks might partition this site is through different times of maximum diel abundance. Carcharhinus melanopterus, C. amblyrhynchos and Negaprion acutidens had distinct diel patterns of attendance, with detection peaks at around 13:00 to $14: 00 \mathrm{~h}$ (adult C. melanopterus and C. amblyrhynchos) and 10:00 $\mathrm{h}$ ( $N$. acutidens). Based on the high hourly overlap between C. melanopterus and C. amblyrhynchos, at least the adults of these 2 species do not appear to partition this habitat by time alone, but juvenile C. melanopterus and $N$. acutidens peaked outside these times, suggesting avoidance of larger size classes by juveniles. The juvenile $C$. amblyrhynchos also had more detections outside of the peak for adult $C$. amblyrhynchos and C. melanopterus, although limited data preclude extrapolation of results for juveniles of this species. The spatial segregation of adult and juvenile size classes has been well documented (Speed et al. 2010), although partitioning of habitats by time has been explored less. Smaller sharks might avoid adult aggregation sites during peak attendance periods to reduce predation risk. However, potential tag collisions during peak adult aggregation periods, resulting in fewer detections of juvenile C. melanopterus and $N$. acutidens, cannot be discounted. Our observation of comparatively fewer detections of adult sharks at night than during the day supports the refuging hypothesis and suggests that some individuals move into the lagoon at night to forage.

Visual censuses identified that aggregations were most common in the south zone of Skeleton Bay. Core areas of use for Carcharhinus melanopterus occurred at both the southern and northern ends of the bay. In contrast to the visual census, combined $50 \%$ KD estimates for C. melanopterus suggest that more individuals use the northern end of the bay than the southern. This discrepancy might also have been due to difficulties associated with counting sharks accurately in the coral-dominated north zone. The core area used by C. amblyrhynchos was comparatively small and overlapped with the other species, notably Triaenodon obesus, at the northern end of the array. Habitat partitioning with considerable overlap among C. melanopterus, T. obesus and C. amblyrhynchos has also been previously identified (Nelson \& Johnson 1980, McKibben \& Nelson 1986). It is therefore unlikely that these 3 species spatially partition habitats within the aggregation site; however, C. amblyrhynchos and T. obesus were detected comparatively less often than C. melanopterus and $N$. acutidens at the southern end of the array. While we observed little evidence of habitat partitioning, it is possible that these species partition habitats at a larger scale outside of the study site. We also confirmed previous findings of sand flat preferences for C. melanopterus and juvenile $N$. acutidens (McKibben \& Nelson 1986, White \& Potter 2004).

All species displayed inter-annual site fidelity, a behaviour observed commonly in many species of coastal sharks (Speed et al. 2010). Site fidelity has been observed in reef sharks at a number of remote islands or atolls (Stevens 1984, Garla et al. 2006, Chapman et al. 2009, Papastamatiou et al. 2009a, Field et al. 2011), although fewer studies have addressed this topic on fringing or barrier reef systems (e.g. Heupel et al. 2010). Our results demonstrate that even in a vast, contiguous, fringing reef system, such as Ningaloo Reef, reef sharks frequently return to a specific site $(\sim 1.5 \mathrm{~km}$ long) across years. This result contrasts with those from a movement study of Carcharhinus amblyrhynchos on the Great Barrier Reef, where little evidence of site 
fidelity, particularly in adults, was observed over 6 mo (Heupel et al. 2010). Site fidelity differences between our study and that by Heupel et al. (2010) for C. amblyrhynchos might be due to environmental or habitat differences between locations, or result from differences in the length of monitoring periods (28 vs. 6 mo, respectively). Site fidelity can arise because of the benefits associated with food availability, protection from predators, or reproduction (Speed et al. 2010). We found little evidence of foraging, although courtship behaviour during aggregations suggests that long-term repeated use of this area might be indicative of 'mating site fidelity'. Given that C. amblyrhynchos and $C$. melanopterus numbers are highest during the afternoon in Skeleton Bay, use of this area across years by these species might also be related to favourable environmental conditions (e.g. water temperature, tide height), as has been observed in several species (Speed et al. 2010).

Results from the performance of the acoustic array provided further information on the suitability of this method for monitoring reef shark aggregations. Detection range was comparable to other acoustic arrays used for monitoring reef sharks (Field et al. 2011), and the positioning error and receiver performance metrics were also similar to those in a previous study (Simpfendorfer et al. 2002). Potential sources of interference with detections, such as boat traffic and biological noise, were probably minimal due to boat restrictions into the study site and low positive noise quotients (Simpfendorfer et al. 2008). However, the increase in the negative noise quotients during peak aggregation periods suggests that detections were likely affected by tag collisions during these times of high use (Simpfendorfer et al. 2008). Given that shark aggregations were present in the study area throughout the day, it is unlikely that a failure to detect animals was due to tag collisions. A steady increase in the rejection coefficient throughout the course of the study also suggests tag collision; however, the mean rejection coefficient overall (0.012) was similar to that determined by Simpfendorfer et al. (2008) (0.041), which indicates that the array was performing reliably on average.

\section{CONCLUSIONS}

We have quantified the spatial and temporal patterns of an inshore reef shark aggregation in northern Western Australia and have identified limited evidence of habitat partitioning among 4 coexisting species within the aggregation site. The combination of acoustic monitoring and visual censuses permitted both long-term and behavioural observations. Aggre- gations of reef sharks displaying potential courtship behaviour and the presence of juveniles over several years indicate this area is potentially important to reef shark reproductive activities and juvenile development. Future studies should determine whether a common resource (environmental conditions) contributes to reef shark aggregations and long-term use of specific sites. Increasing pressure from coastal development and fishing pose potential threats to coastal shark aggregations; 4 tagged sharks, including the individual recaptured during the present study, have been caught by recreational fishers over the course of this and concurrent studies (C. W. Speed et al. unpubl. data). We therefore recommend that known shark aggregation sites such as Skeleton Bay are managed closely through the use of sanctuary zone restrictions, particularly during peak aggregation periods.

Acknowledgements. This study was funded by the Australian Institute of Marine Science and the Australian Commonwealth Scientific and Industrial Research Organisation. Receiver data was provided through the Australian Animal Tracking and Monitoring System (AATAMS), a facility of Integrated Marine Observing System. AATAMS also provided in-kind support and technical assistance. Field work was done in compliance with research permits supplied by the Department of Environment and Conservation and the Western Australian Department of Fisheries (SF7536, CE002881 and 1719-2010-39). Animal ethics for all animal handling was approved by the Charles Darwin University Animal Ethics Committee (A07035). We thank O. O'Shea, R. McAuley, J. Ruppert, F. Wiley, S. Baccarella, P. Haskell, D. Simpson, C. Lochu, F. Cerutti and S. Ridley for assistance with field work, and C. Simpfendorfer, R. Fisher, M. Case and B. Radford for advice and assistance with analysis.

\section{LITERATURE CITED}

Beyer HL (2004) Hawth's analysis tools for ArcGIS. Available at www.spatialecology.com/htools

Burnham KP, Anderson DR (2002) Model selection and multimodal inference: a practical information-theoretic approach. Springer-Verlag, New York, NY

Chapman DD, Pikitch EK, Babcock E, Shivji MS (2005) Marine reserve design and evaluation using automated acoustic telemetry: a case study involving coral reefassociated sharks in the Mesoamerican Caribbean. Mar Technol Soc J 39:42-55

> Chapman DD, Babcock EA, Gruber SH, Dibattista JD and others (2009) Long-term natal site-fidelity by immature lemon sharks (Negaprion brevirostris) at a subtropical island. Mol Ecol 18:3500-3507

Chatfield C (1996) The analysis of time series. An introduction. CRC Press, Boca Raton, FL

Cortés E (1999) Standardized diet compositions and trophic levels of sharks. ICES J Mar Sci 56:707-717

DeAngelis BM, McCandless CT, Kohler NE, Recksiek CW, Skomal GB (2008) First characterization of shark nursery habitat in the United States Virgin Islands: evidence of habitat partitioning by two shark species. Mar Ecol Prog Ser 358:257-271

Dudley SFJ, Cliff G, Zungu MP, Smale MJ (2005) Sharks 
caught in the protective gill nets off KwaZulu-Natal, South Africa. 10. The dusky shark Carcharhinus obscurus (Lesueur, 1818). Afr J Mar Sci 27:107-127

> Duncan KM, Holland KN (2006) Habitat use, growth rates and dispersal patterns of juvenile scalloped hammerhead sharks Sphyrna lewini in a nursery habitat. Mar Ecol Prog Ser 312:211-221

Economakis AE, Lobel PS (1998) Aggregation behavior of the grey reef shark, Carcharhinus amblyrhynchos, at Johnston Atoll, Central Pacific Ocean. Environ Biol Fishes 51: 129-139

Field IC, Meekan MG, Speed CW, White W, Bradshaw CJA (2011) Quantifying movement patterns for shark conservation at remote coral atolls in the Indian Ocean. Coral Reefs 30:61-71

> Friedlander AM, DeMartini EE (2002) Contrasts in density, size, and biomass of reef fishes between the northwestern and the main Hawaiian islands: the effects of fishing down apex predators. Mar Ecol Prog Ser 230:253-264

Garla RC, Chapman DD, Wetherbee BM, Shivji MS (2006) Movement patterns of young Caribbean reef sharks, Carcharhinus perezi, at Fernando de Noronha Archipelago, Brazil: the potential of marine protected areas for conservation of a nursery ground. Mar Biol 149:189-199

Gruber SH, Nelson DR, Morrissey JF (1988) Patterns of activity and space utilization of lemon sharks, Negaprion brevirostris, in a shallow Bahamian lagoon. Bull Mar Sci 43: 61-76

> Heupel MR, Simpfendorfer CA (2005) Quantitative analysis of aggregation behavior in juvenile blacktip sharks. Mar Biol 147:1239-1249

> Heupel MR, Simpfendorfer CA, Collins AB, Tyminski JP (2006) Residency and movement patterns of bonnethead sharks, Sphyrna tiburo, in a large Florida estuary. Environ Biol Fishes 76:47-67

> Heupel MR, Carlson JK, Simpfendorfer CA (2007) Shark nursery areas: concepts, definition, characterization and assumptions. Mar Ecol Prog Ser 337:287-297

> Heupel MR, Simpfendorfer CA, Fitzpatrick R (2010) Largescale movement and reef fidelity of grey reef sharks. PLoS ONE 5:e9650

Hight BV, Lowe CG (2007) Elevated body temperatures of adult female leopard sharks, Triakis semifasciata, while aggregating in shallow nearshore embayments: Evidence for behavioural thermoregulation? J Exp Mar Biol Ecol 352:114-128

> Johnson RH, Nelson DR (1978) Copulation and possible olfaction-mediated pair formation in two species of carcharhinid sharks. Copeia 1978:539-542

Klimley PA, Nelson DR (1981) Schooling of the scalloped hammerhead shark, Sphyrna lewini, in the Gulf of California. Fish Bull 79:356-360

Klimley PA, Nelson DR (1984) Diel movement patterns of the scalloped hammerhead shark (Sphyrna lewini) in relation to El Bajo Espirito Santo: a refuging central-position social system. Behav Ecol Sociobiol 15:45-54

Last PR, Stevens JD (2009) Sharks and rays of Australia, 2nd edn. CSIRO Publishing, Collingwood

Lyle JM (1987) Observations on the biology of Carcharhinus cautus (Whitley), C. melanopterus (Quoy \& Gaimard) and C. fitzroyensis (Whitley) from northern Australia. Aust J Mar Freshw Res 38:701-710

> McAuley RB, Simpfendorfer CA, Hyndes GA (2007) Distribution and reproductive biology of the sandbar shark, Carcharhinus plumbeus (Nardo), in Western Australian waters. Mar Freshw Res 58:116-126

McCauley DJ, Papastamatiou YP, Young HS (2010) An obser- vation of mating in free-ranging blacktip reef sharks, Carcharhinus melanopterus. Pac Sci 64:349-352

McKibben JN, Nelson DR (1986) Patterns of movement and grouping of gray reef sharks, Carcharhinus amblyrhynchos, at Enewetak, Marshall Island. Bull Mar Sci 38: 89-110

> Meekan MG, Bradshaw CJA, Press M, McLean C, Richards A, Quasnichka S, Taylor JG (2006) Population size and structure of whale sharks Rhincodon typus at Ningaloo Reef, Western Australia. Mar Ecol Prog Ser 319:275-285

Nelson DR, Johnson RH (1980) Behavior of reef sharks of Rangiroa, French Polynesia. In: National Geographic Society Research Reports (1968-1985). National Geographic Society Research Report 12:479-499. National Geographical Society, Washington, DC

Papastamatiou YP, Caselle JE, Friedlander AM, Lowe CG (2009a) Distribution, size frequency, and sex ratios of blacktip reef sharks Carcharhinus melanopterus at Palmyra Atoll: a predator-dominated ecosystem. J Fish Biol 75:647-654

Papastamatiou YP, Lowe CG, Caselle JE, Friedlander AM (2009b) Scale-dependent effects of habitat on movement and path structure of reef sharks at a predator-dominated atoll. Ecology 90:996-1008

Papastamatiou YP, Friedlander AM, Caselle JE, Lowe CG (2010) Long-term movement patterns and trophic ecology of blacktip reef sharks (Carcharhinus melanopterus) at Palmyra Atoll. J Exp Mar Biol Ecol 386:94-102

Pikitch EK, Chapman DD, Babcock EA, Shivji MS (2005) Habitat use and demographic population structure of elasmobranchs at a Caribbean atoll (Glover's Reef, Belize). Mar Ecol Prog Ser 302:187-197

Porcher IF (2005) On the gestation period of the blackfin reef shark, Carcharhinus melanopterus, in waters off Morea, French Polynesia. Mar Biol 146:1207-1211

Pratt HL, Carrier JC (2001) A review of elasmobranch reproductive behavior with a case study on the nurse shark, Ginglymostoma cirratum. Environ Biol Fishes 60:157-188

Randall JE, Helfman GS (1973) Attacks on humans by the blacktip reef shark (Carcharhinus melanopterus). Pac Sci 27:226-238

Robbins WD, Hisano M, Connolly SR, Choat HJ (2006) Ongoing collapse of coral-reef shark populations. Curr Biol 16:2314-2319

Simpfendorfer CA, Heupel MR, Hueter RE (2002) Estimation of short-term centers of activity from an array of omnidirectional hydrophones, and its use in studying animal movements. Can J Fish Aquat Sci 59:23-32

Simpfendorfer CA, Freitas GG, Wiley TR, Heupel MR (2005) Distribution and habitat partitioning of immature bull sharks (Carcharhinus leucas) in a southwest Florida estuary. Estuaries 28:78-85

Simpfendorfer CA, Heupel MR, Collins AB (2008) Variation in the performance of acoustic receivers and its application for positioning algorithms in a riverine setting. Can J Fish Aquat Sci 65:482-492

Sims DW (2003) Tractable models for testing theories about natural strategies: foraging behaviour and habitat selection of free-ranging sharks. J Fish Biol 63(Suppl A):53-73

Sims DW, Merrett DA (1997) Determination of zooplankton characteristics in the presence of surface feeding basking sharks Cetorhinus maximus. Mar Ecol Prog Ser 158: 297-302

> Smith AK, Pollard DA (1999) Threatened fishes of the world: Carcharias taurus (Rafinesque, 1810) (Odontaspididae). Environ Biol Fishes 56:365

Sokal RR, Rohlf FJ (eds) (1995) Biometry, 3rd edn. W.H. Free- 
man, New York, NY

Speed CW, Field IC, Meekan MG, Bradshaw CJA (2010) Complexities of coastal shark movements and their implications for management. Mar Ecol Prog Ser 408:275-293

Stevens JD (1984) Life-history and ecology of sharks at Aldabra Atoll, Indian Ocean. Proc R Soc Lond B Biol Sci 222:79-106

VEMCO (2007) Technical white paper: understanding the performance of VEMCO $69 \mathrm{kHz}$ single frequency acoustic telemetry. VEMCO, Halifax

Ward-Paige CA, Mora C, Lotze HK, Pattengill-Semmens C, McClenachan L, Arias-Castro E, Myers RA (2010) Largescale absence of sharks on reefs in the greater-Caribbean: a footprint of human pressures. PLoS ONE 5(8):e11968

Weng KC, Boustany AM, Pyle P, Anderson SD, Brown A, Block BA (2007) Migration and habitat of white sharks (Carcharodon carcharias) in the eastern Pacific Ocean.

Editorial responsibility: John Choat,

Townsville, Australia
Mar Biol 152:877-894

- Wetherbee BM, Gruber SH, Rosa RS (2007) Movement patterns of juvenile lemon sharks Negaprion brevirostris within Atol das Rocas, Brazil: a nursery characterized by tidal extremes. Mar Ecol Prog Ser 343:283-293

White WT, Potter IC (2004) Habitat partitioning among four elasmobranch species in nearshore, shallow waters of a subtropical embayment in Western Australia. Mar Biol 145:1023-1032

Whitney NM, Pratt HL, Carrier JC (2004) Group courtship, mating behaviour and siphon sac function in the whitetip reef shark, Triaenodon obesus. Anim Behav 68:1435-1442

> Yeiser BG, Heupel MR, Simpfendorfer CA (2008) Occurrence, home range and movement patterns of juvenile bull (Carcharhinus leucas) and lemon (Negaprion brevirostris) sharks within a Florida estuary. Mar Freshw Res 59: 489-501

Submitted: November 11, 2010; Accepted: February 8, 2011 Proofs received from author(s): April 28, 2011 